\title{
Frameworks for Innovation, Collaboration, and Change: Value Creation Wheel, Design Thinking, Creative Problem-Solving, and Lean $^{1,2}$
}

\section{Luis Filipe Lages ${ }^{1}$}

VCW Lab at Nova SBE, Nova School of Business and Economics, Universidade Nova de

\author{
Lisboa, Portugal \\ 1 lflages@novasbe.pt \\ Antonin Ricard ${ }^{2}$, Aurélie Hemonnet-Goujot ${ }^{3}$, Anne-Marie Guerin ${ }^{4}$ \\ Aix-Marseille University- IAE, CERGAM, Aix-en-Provence, France \\ ${ }^{2}$ antonin.ricard@iae-aix.com, ${ }^{3}$ aurelie.hemonnet@iae-aix.com, \\ ${ }^{4}$ anne-marie.guerin@iae-aix.com
}

\section{Main message}

The Value Creation Wheel (VCW) is the decision-making meta-framework recommended to address innovation, collaboration, and change challenges in formal relationships.

\footnotetext{
${ }^{1}$ JEL classification codes: M00, O14, O31, O32, O35, O38, P13, Q01
}

2 The first author acknowledges the support of Fundação para a Ciência e a Tecnologia (UID/ECO/00124/2013 and Social Sciences DataLab, Project 22209), POR Lisboa (LISBOA-01-0145FEDER-007722 and Social Sciences DataLab, Project 22209), and POR Norte (Social Sciences DataLab, Project 22209). He also acknowledges the countless professionals, executives, scientists, professors, researchers, and students who contributed during the past two decades to the development of the Value Creation Wheel. The authors also acknowledge the support of the Centre d'Etudes et de Recherche en Gestion d'Aix Marseille (CERGAM). 


\section{Key points}

The Value Creation Wheel (VCW) can integrate, complement, or be joined with other frameworks, tools, and theories to address the challenges of formal relationships. The VCW's ability to incorporate intra- and inter-organizational insights emerging from internal and external stakeholders is especially useful in solving the challenges of collaborative arrangements.

VCW solutions are often more realistic than Design Thinking, Creative Problem-Solving, and Lean because they accommodate the views of various stakeholders about ideas and filters, and because key decision makers (KDM) must be involved in the main stages of the decision-making process.

\section{Introduction}

Organizations and managers face daily challenges that are all but linear. The business world is global and local, flat and irregular, adding complexity to problem-solving. Organizations are being challenged to collaborate and create shared value (CSV), while considering the needs of society. In order to innovate, grow, and address organizational challenges, organizations are being challenged to involve internal and external stakeholders and provide them with the tools to become partners and CSV (McManus, 2019; Mendy, 2019; Porter and Kramer, 2011). Similarly, in order to deal with today's constant need for innovation, collaboration, and change (IC\&C), new problem-solving frameworks are now 
expected to be simultaneously structured and agile and provide solutions via collective intelligence, co-creation, and partnerships (Lages, 2016).

Because of increasing globalization and the importance of collaboration, research dedicated to formal relationships has become popular in the last two decades (Gomes et al., 2011; Gomes et al., 2016). Nowadays, there are many articles examining formal interorganizational collaboration across markets (for example, mergers and acquisitions (M\&A), strategic alliances, joint ventures, franchising, global value chains, and business model restructuring). Although these types of formal partnerships are essential for a firm's constant IC\&C, they present several challenges in the form of trust, control, confidence, contract and negotiation, commitment, and cultural issues (Gomes et al., 2016), cooperation vs. competition, participation values, productivity, and performance (Wong et al., 2017), value appropriation and risk-return trade-offs (Contractor \& Woodley, 2015), and shared value and sustainability (Lee, 2019). Many of these challenges might be addressed by applying the problem-solving collaborative frameworks often used in the context of informal forms of cooperation. Surprisingly, the literature has not explored how these collaborative frameworks could be applied in the context of formal relationships, and which one(s) would be more appropriate for which contexts. This article proposes to fill this gap by comparing four popular problem-solving frameworks: the Value Creation Wheel (VCW), Design Thinking (DT), Creative Problem-Solving (CPS), and Lean.

This study contributes to the literature on formal partnerships and to managerial practice on three levels. First, it explores the extent to which different problem-solving frameworks 
traditionally used in informal relationships can bring added value to a context of formal partnerships. Much of the research in formal partnerships to date has explored the reasons for entering into an agreement vs. going it alone (Beamish \& Lupton, 2016) and the relationship between internal and external cooperation (Hillebrand \& Biemans, 2003; Mudambi \& Tallman, 2010; Stettner \& Lavie, 2014). To our knowledge, no research explores how traditional problem-solving frameworks (VCW, DT, CPS, and Lean) could be used to enhance cooperation in formal collaboration with lower risk. The application of these four frameworks might have important implications because they can be applied as a halfway compromise between a pure informal collaboration and a more formal collaboration for solving organizational challenges, namely in the pre- and/or postagreement phases.

Second, after analyzing and comparing the four frameworks, this study focuses on the VCW. The VCW works very well in the context of formal relationships because it is a structured and flexible meta-framework that can include, complement, or be integrated into other tools and frameworks (including DT, CPS, and Lean). Since it is an innovation framework it might be integrated into, incorporate, or complement several front-end innovation frameworks (for example, innovation life cycle, value proposition canvas, fivedays design sprint, value proposition canvas) as well as back-end frameworks (for instance, Customer Development Process, innovation life cycle, Business Model Canvas). Often, it triggers the decision to use DT (for example, for new product development purposes), CPS (for instance, to communicate across diverse teams), Lean (for instance, to optimize the production process), Blue Ocean Strategy (BOS) (for instance, to identify new market 
spaces and determine how to cut costs while increasing value), Lean Startup (for instance, to develop minimum viable products), Business Model Canvas (BMC) (which, for instance, identifies the value proposition that underpins description, analysis, design, and development of a business model), and Customer Development Process (for example, to search and execute the business model), among others.

Finally, it is well known that interest is growing in topics of leadership and in the human side of formal partnerships (Ferrary, 2015; Gomes et al., 2016). Due to its ability to accommodate intra- and inter-organizational insights emerging from internal and external stakeholders, the VCW can easily be applied to solve several challenges of collaborative arrangements across diverse sectors. VCW outcomes are especially realistic because they require the KDMs to be committed to, and involved in, the main phases of the VCW problem-solving process (definition of the challenge, selection of best ideas, ranking of filters, and implementation phase).

The remainder of this article is organized as follows: The next section presents the research approach used in this study, followed by a section in which the four collaboration frameworks for problem-solving (VCW, DT, CPS, and Lean) are reviewed. The four frameworks are then compared in the context of formal partnerships and we propose that, due to its unique characteristics, the VCW meta-framework is the most suitable problemsolving framework to address a wide range of challenges. The findings of our exploratory study are then presented and several VCW projects in formal relationships are presented. This is followed by the discussion and directions for future research. 


\section{Research approach}

This study is exploratory, and is aligned with other research in the field of formal relationships (such as strategic alliances) in which about a third of the articles published in top journals are exploratory and a fifth are conceptual, dedicated to formulating theories and ideas (Gomes et al., 2016). Considering that no analysis of the four problem-solving frameworks (VCW, DT, CPS, and Lean) in the context of formal partnerships is reported in the literature, our research questions are as follows:

1) Could the four problem-solving frameworks be used in the context of pre- and/or postagreement phases?

2) If the answer is yes, which framework could be the most appropriate to address challenges in the context of formal partnerships?

After determining that the VCW is more appropriate to address challenges of formal relationships, this study explores a three-year period database (2016-2018) of VCW projects in formal partnerships. Our exploratory sample comprises cases in which the VCW was used to address challenges in the context of collaborative arrangements such as M\&A, strategic alliances, joint ventures, franchising, global value chains, and business model restructuring. This sample is diverse in terms of problems/challenges, industry, and nationalities and allows us to better understand the dynamics and processes used by companies when applying the VCW in formal partnerships. 


\section{Review of the four problem-solving frameworks}

In this section we start by discussing in detail each of the four problem-solving approaches (VCW, DT, CPS, and Lean), their limitations, and the extent to which they are aligned with today's changing environment. We then explain how each of them can be applied in the context of formal relationships to deal with IC\&C.

\section{The Value Creation Wheel}

\section{$\underline{\text { VCW definition }}$}

The VCW is a meta-framework designed to help KDMs and their teams solve various challenges. The VCW is particularly useful for KDMs and teams who believe in cocreation, collective intelligence, and collective thinking. First, the KDMs define a challenge/problem using the VCW. Second, through co-creation, the VCW helps them identify a range of solutions and criteria/filters to solve the challenge/problem. Third, the KDMs select the solutions and rank the criteria. Finally, the VCW filters the ideas and helps to implement the final solution(s). In the words of the CEO of a pharmacy company, "the Value Creation Wheel model is very useful to understand reality, to model it, and then to use it for policy making" (Villax, 2017).

The VCW defines the KDM as a leader who is committed, has the power, and has the 3Ms (manpower, minute and money) to solve a challenge/problem at the organizational and/or individual level. Depending on the context, we can all be KDMs. Often, there are situations in which there is a group of KDMs who need to be aligned in order to solve some challenges. Examples of KDMs include CEOs, directors of departments, intra- and 
entrepreneurs, consumers, and ourselves while managing our daily lives. Access to the $3 \mathrm{Ms}$ is essential to be a KDM. The KDMs need to be committed to, and involved in, solving the challenge/problem because in the VCW process they are the only ones who can really identify and define the challenge/problem and implement the final solution. In addition to KDMs, the VCW can be used by everyone - such as employees, consultants, and other stakeholders - who is empowered and wants to help KDMs solve their challenges and improve their decision-making. The VCW supports the belief that a company's success and social progress are interdependent, and therefore that organizations should consider the needs of society (Drucker, 1984; Mendy, 2019; Porter and Kramer, 2011). In order to address organizational challenges and create shared value, internal and external stakeholder involvement is crucial. The VCW can create shared value by helping both KDMs and society solve a wide range of complex challenges/problems. Through an established problem-solving process and collective intelligence, the VCW can overcome challenges such as problem complexity, lack of support, lack of choice, too many options, lack of creativity and imagination, and difficulty accommodating different perspectives (VCW, 2019).

\section{$\underline{\mathrm{VCW} \text { process }}$}

The original VCW framework had its origins about two decades ago in the fields of marketing and international business. At that time, the main research focus was to better understand how firms could grow and become profitable (Lages, 1999), how the circular process based on past key performance indicators (KPIs) would affect strategy, and how 
this strategy would improve future performance (Lages, 2000a; Lages et al., 2008). Having matured now and comprising five phases (see Figure 1), the VCW is commonly employed to address a broader range of complex challenges in formal partnerships, during both the pre- and post-agreement phases.

\section{Insert Figure 1 about here}

In the first phase the VCW process analyses the context of the underlying challenge. Then the Key Decision Makers (KDMs) define the problem to initiate the VCW process and establish the Key Performance Indicators (KPIs). Second, the VCW moves to the generation of solutions and filters (that is, criteria to select the most/least important solutions). The steps of generation of solutions and production of filters should occur independently of each other. In the third phase, the KDMs select and prioritize the key ideas and the main filters/criteria. Fourth, the Value Creation Funnel (VCF) is applied to all the ideas that were accepted by the KDMs in Phase 3 by crossing the selected ideas with the ranked filters, often supported by Multi Criteria Decision Analysis. Following the VCF, the final solution(s) is(are) conceptualized and prototyped. In the fifth phase, the solution(s) is(are) presented to the KDMs, tested, and implemented considering the 3Ms (Manpower, Minute, and Money). If applicable, a business model and/or business plan might also be developed. At any time, it is possible to jump back to a previous stage; the KDMs decide on "go", "no go", or "go back" to previous stages of the VCW. The VCW can be used to solve a wide range of problems following paradox approaches, that is, structured and agile, 
slow and dynamic, or sequential and circular. According to the senior partner of a top-five human resources management (HRM) consulting firm involved in a past project:

The VCW is an ample model in terms of thinking, which starts from a statement, generates ideas and filters, has a moment of decision making and concept development. We can use it for broad problems as well as for concrete problems.

\section{VCW outcomes}

First, the VCW guides KDMs and others to generate customized solutions for a specific problem. It facilitates solutions for trade-offs and complex paradoxes, such as how to benefit from economies of scale and satisfy local market needs, how to create value while cutting costs, and how to bridge the "what" and the "why" and technology and the market. Moreover, it can be used to respond to problems/challenges that linear/rigid frameworks or highly unstructured/chaotic frameworks cannot solve. Second, the VCW clarifies the decision-making process by facilitating the generation of ideas and their selection criteria. It encourages diverse solutions and filters while respecting relevant inputs. Third, the VCW offers the ability to involve different stakeholders in organization and co-creation. It includes inputs from people with diverse positions, C-Level and front-line people, people thinking "in boxes" and people with "no boxes," internal and external stakeholders, techpush and market-pull mindsets, as well as lead users and late adopters (Jahanmir \& Lages, 2015, 2016; Lages, 2016). It can incorporate different and/or conflicting perspectives and avoid hierarchy that kills individual creativity. Unlike traditional customer-centric frameworks, the VCW addresses stakeholder engagement/buy-in and KDM involvement. Fourth, the VCW can be used to support management of IC\&C by converging conflicting 
ideas into common solutions, complementing and/or integrating existing solutions. The $\mathrm{VCW}$ is a dynamic, interactive, circular framework that incorporates constant feedback and benefits from cooperation and co-creation. Overall, there is a sensation of empowerment and ownership because the KDMs and stakeholders with the problem also become part of the solution(s).

$\underline{\mathrm{VCW}}$ as a framework to support formal relationships

The VCW is relatively simple in the context of formal partnerships because it is a metaframework that can join, complement, or be integrated into other tools and frameworks. As such, application of the VCW might trigger the decision to use tools from specific sectors or generalist frameworks like DT (for example, for new product development purposes), CPS (for example to communicate across diverse teams), Lean (for example to optimize the production process), SWOT, Porter 5 Forces, Boston Consulting Group and McKinsey matrices, Blue Ocean Strategy (BOS), or Business Model Canvas (BMC), among others. This is one of the major advantages of being a meta-framework.

During the pre-agreement phase of formal partnerships, the VCW might be used to address a wide range of critical challenges, such as motives for collaboration, how to select the right partner, what and how to negotiate, and how to agree on supporting contracts (Doz, 1996; Doz et al., 2000; Glaister \& Buckley, 1996; Parkhe, 1993). Organizations in the preor post-agreement phase are required to deal with a wide range of conflicting goals, which requires both planning and improvisation capabilities (Asseraf et al., 2018). 
The VCW might also be used to address specific challenges arising in the post-agreement phase, such as cross-cultural and effective management, and determinants of company performance (Brouthers \& Bamossy, 2006; Buckley et al., 2009; Luo, 2001; Reuer et al., 2002).

\section{$\underline{\text { VCW limitations }}$}

The VCW should not be used when the KDMs: a) are neither involved nor committed to the problem and the VCW process, b) have no power and/or access to the $3 \mathrm{Ms}$, and/or c) do not believe in co-creation and innovation for idea generation and problem-solving. At the organizational level, some people see the VCW as a C-Level and top-down framework. However, depending on the profile of the KDMs and culture, the VCW might be applied using top-down and/or bottom-up strategic management. For instance, Geert Hofstede's seminal work found that French managers think of their ideal organization as a "pyramid of people," German managers as a "well-oiled machine," and British managers as a "village market," and these perspectives were reflected in the ways in which managers, consultants, professors, and students would look at managing local organizations (Kieser, 1994).

Some criticize the VCW for its requirement to involve the KDMs in the VCW process for problem-solving. This requirement is included because the VCW is oriented toward concrete solutions (go vs. no go vs. go back). For instance, while in DT, CPS, and Lean there are iterations with the customer and/or stakeholders, the non-involvement of KDMs at critical stages often justifies the frustration of not succeeding due to non-alignment with the KDMs' vision and strategy, which then leads to failure and wasted resources. Moreover, 
past research indicates that KDMs are critical to bring human and social capital that support a firm's innovation strategy (Allemand et al., 2017).

Another frequent comment about the VCW is that the moment the process is concluded, there is always space to revisit the wheel (for example, to look for new ideas, new filters, redesign the funnel or the prototype) or initiate a new process (for example in response to a new problem/challenge, or a more focused problem/challenge) and this reflects what happens in real life. Contrary to past static frameworks, or to other problem-solving methodologies like Lean, the VCW follows an agile stage-gate approach to progress in the sense that it is possible to take a step back at any time. However, due to different time perspectives and cultural backgrounds of the managers involved (Lewis, 2014), one may observe that, when solving challenges, different cultures tend to apply the VCW in different ways. For instance, some see the VCW as a "5 stage-gate sequential approach" (USA, Germany), others prefer to see the VCW as a "circular approach" (Hong Kong and China), and others use the VCW as a "hybrid ellipse approach" (France, Portugal).

\section{Design Thinking}

\section{$\underline{\text { DT definition }}$}

DT has recently gained popularity as a collaborative problem-solving tool, as managers increasingly acknowledge design as a strategic resource (Carlgren, Elmquist et al., 2016). The DT framework — disseminated by IDEO founder David Kelly and Stanford University's d.school consists of applying the processes of how designers think and work across a variety of industries to solve a wide range of complex problems (Brown, 2010). 
DT involves creative tools such as storytelling, prototyping, and experimentation to address complex managerial activities (Brown, 2010; Carlgren et al., 2014b). While representing a new creative and innovative approach for practitioners, for the academic world DT lacks a strong theoretical foundation as a management tool (Johansson-Sköldberg et al., 2013; Liedtka, 2015). DT is based on a multidisciplinary, human-centered approach that combines abductive thinking, oscillating between analytical and creative modes of reasoning (Liedtka, 2015; Martin, 2009). According to Brown (2010), CEO of the design consultancy firm IDEO and one of the leading proponents of DT, it aims to satisfy three conditions: a) desirability (what makes sense for the consumer/final user), b) feasibility (what is technically possible in the near future), and c) viability (how to develop a profitable project).

\section{$\underline{\text { DT process }}$}

DT is based on: 1) gathering data about user needs, 2) idea generation, and 3) testing (Liedtka, 2015). These processes can be summarized in three stages: inspiration, idea generation or ideation, and implementation. First, inspiration is based on a "user-oriented" approach favoring the identification of new insights, the understanding of latent desires, and the detection of new opportunities (Veryzer \& Borja de Mozota, 2005). Since collaboration is at the center of DT (Seidel \& Fixson, 2013), multidisciplinary teams of experts are assembled (such as psychologists, anthropologists, engineers, designers). Techniques such as observation and ethnography allow developing empathy toward users and acquiring a better understanding of their use problems (Leonard \& Rayport, 1997). 
Second, ideation consists of generating and iteratively testing new concepts after brainstorming and focus group sessions, with the help of rapid prototyping (Brown, 2010). Using numerous sketches or models makes it possible to explore multiple ideas in parallel. The goal is to identify new directions that can advance prototypes that are more precise and detailed. Ideation enables evaluating not only the functional dimension of an idea but also its aesthetic and emotional dimensions. Furthermore, it makes communication more efficient, requiring each team member to focus, and it favors evaluation, decision-making, and project pace acceleration (Brown, 2010). Third, implementation consists of technically developing prototypes while integrating profitability constraints. It is about "communicating an idea with sufficient clarity to gain acceptance across the organization, proving it and showing that it will work in its intended market" (Brown, 2010, p. 107). Similar processes have been developed by Stanford University (2009), whose d.school proposes a five-step iterative framework: empathize (collect data based on users' observations), define (synthesize data to refine problem understanding), ideate (suggest ideas for solving the problem), make a prototype (develop tangible representations of the ideas), and test (with potential users).

\section{$\underline{\text { DT outcomes }}$}

While originally grounded in new product development, DT is now an approach applied to different sectors (health, FMCG, NGO), for different purposes (new services, business models). It helps managers improve innovation outcomes by reducing decision makers' existing cognitive biases and supporting managerial decisions, even though specific 
mechanisms still need to be specified (Liedtka, 2015; Ricard \& Saiyed, 2015). While this approach was initially designed to apply to the entire innovation process, DT is now used mainly in upstream stages (Carlgren et al., 2014b). In the ideation stage, DT provides a valuable analytical framework, mainly through scenarios and storyboards, which helps to gain a better understanding of user issues. By rapidly integrating the ideas in the user experience through prototyping, DT helps managers get a dynamic perspective of the innovation process. More generally, DT helps to structure the innovation process and develop companies' long-term innovation capabilities (Carlgren et al., 2014a). This analytical framework gives meaning to the ideas generated by other approaches (mobilized internally or by external partners) and can be applied throughout the NDP process and other projects (Hemonnet-Goujot et al., 2016).

\section{DT as a framework to support formal relationships}

DT is not only dedicated to creating successful user-focused solutions, it can also be applied to large and complex problems such as designing new strategies and business models (Carlgren, Elmquist et al., 2016; Liedtka, 2011; Micheli et al., 2019). When dealing with collaborative methods of development such as M\&A or joint ventures, DT can support these growth strategies in both the pre-agreement stage (by considering potential new business models) and in the post-agreement stage (by managing the brand portfolio) (Beverland et al., 2015). Furthermore, in the post-agreement phase, because it is a Knowledge Intensive Business Service (KIBS), DT can help to enhance product-service innovation in multinational manufacturing enterprises that require better understanding and 
engagement with customers (Vendrell-Herrero et al., 2018). Notably, outsourcing external design is a means of increasing the innovativeness of new product-service offerings and their success, provided some specific conditions such as relationship commitment are respected (Carmeli et al., 2017; Hemonnet-Goujot et al., 2019). One example of DT in practice is in better framing the post-agreement stage by refining a brand portfolio and improving the positioning of existing brands. In the inspiration stage, DT will first define the challenge for each brand (including considering the position each brand should adopt). Second, observation of people is carried out, as well as interviews and focus groups (possibly with the help of multidisciplinary teams including marketers and sociologists), to better understand what the uses of products are, identify experts, and collect insights. In the ideation stage, DT can help to frame opportunities for each brand that can be further enriched by brainstorming sessions to, for instance, better understand different uses of products in various scenarios. In the implementation stage, DT might provide brands with new distinct concepts whose economic viability and feasibility will be fine-tuned thanks to iterations with the DT team and tests results.

\section{$\underline{\text { DT limitations }}$}

DT is still a rather loose tool in innovation management, suffering from lack of consensus and theoretical support (Carlgren, Rauth et al., 2016; Iskander, 2018; Liedtka, 2015). DT faces many challenges in terms of method definition, performance, and organizational acceptance. First, although DT allows an iterative process of creativity, the protocol still lacks precision on several key aspects: specific roles for each actor, methods for analyzing 
and interpreting observations, and clear iteration processes in the ideation stage (HemonnetGoujot et al., 2016). Furthermore, DT tends to be mobilized by multidisciplinary teams, many of which are novices in the field of design (Seidel \& Fixson, 2013) —and, by viewing the designer as the single most important gatekeeper in the problem-solving process (Iskander, 2018), it disregards the perspectives of skeptics and other broader views.

DT faces additional challenges in organizations in that there can be: a poor fit with existing processes and structures; difficulty in implementing resulting ideas and concepts; difficulty in demonstrating the value of DT solutions; conflict between DT principles/mindsets and organizational culture; a sense of threat to existing power dynamics; a belief that skills are hard to acquire; different communication styles (Carlgren, Elmquist, et al., 2016).

Third, despite the progressive diffusion of the DT approach, its performance and contribution to organizations' innovativeness remains unclear. While valuing the implementation of an iterative creativity process, DT seems to be applied by organizations as a classic innovation management process, limiting creativity and generating mostly incremental innovation (Iskander, 2018; Nussbaum, 2011). Despite these shortcomings, and even if some DT practices are not new and have already been discussed in the innovation and new product development literature (empathy, observation, brainstorming), DT is recognized as being a distinctive and coherent integrating process (Liedtka, 2015).

\section{Creative Problem-Solving}

\section{$\underline{\text { CPS definition }}$}


The CPS framework began with Alex Osborn and his work on brainstorming (Osborn, 1953). Osborn's first model sought to make explicit the steps involved in the creative process to help individuals develop creative-thinking skills (Puccio, 1999). In recent years the CPS has become one of the most widely influential creative process models applied in organizational settings (Puccio et al., 2010).

\section{$\underline{\text { CPS process }}$}

The CPS model provides a structured framework for creative thinking principles, tools, and stages (Puccio, 1999). The early version of the CPS framework, best known as OsbornParnes CPS (Parnes, 1967) had five steps: Fact-finding, Problem-finding, Idea-finding, Solution-finding, and Acceptance-finding. It provided a linear form and a balance of separate divergent and convergent thinking phases in every step of the framework. Building on this early version, researchers developed new CPS frameworks that differed in structure as well as form. The CPS model's evolution is well illustrated by the Isaksen and Treffinger (2004) model (see Figure 2). The most recent models propose a cyclical process, as opposed to the linear Osborn-Parnes CPS model. This cyclical process is more flexible and aligned with the spiral-type processes observed in organizations, representing a real problem-solving approach.

\section{Insert Figure 2 about here}

CPS' multiple steps and operations can be grouped into three broad categories (Basadur, 1994; Isaksen \& Treffinger, 2004). First, the challenge of understanding (problem formulation) helps the team to get acquainted with the problem that will be addressed. This 
early stage starts with the identification of the challenge, concern, or opportunity that is the most promising. The next steps consist of gathering information about the problem, leading up to a specific problem formulation that guarantees consistency to the whole approach. Second, the main goal of the idea-generating (or solution-finding) phase is to produce new and unusual ideas to address the challenge and solve the problem. Evaluation and selection activities screen the ideas and solutions to choose the most promising one. These activities can be run during Stage 2 (solution-finding) and/or Stage 3 (preparing for action) depending on the preferred model (Basadur, 1994; Isaksen \& Treffinger, 2004). Third, preparing for action (or planning and execution) consists of identifying what the possible sources of assistance and resistance are, and planning for the implementation of the solution. This phase is critical for the organization to actually implement the creative solution identified to solve the problem.

\section{$\underline{\text { CPS outcomes }}$}

The CPS framework results in a solution to address the problem as well as an action plan with specific recommendations aimed at controlling the effectiveness of these actions and ensuring the support of the key stakeholders. The scope of Basadur's (1994) Simplex model is even wider and culminates with execution of an action plan. This last step is to actually do what was defined in the action plan, revising and adapting it to changes in the environment. The scope of the CPS application is broad: Beyond new product or service ideas generation, the framework is also used to solve common problems such as internal 
efficiency, communication and conflict, or intra-organizational relationships (Souza et al., 2014).

$\underline{\text { CPS as a framework to support formal relationships }}$

The CPS framework is highly flexible and might help to solve diverse problems concerning inter-organizational collaborations, such as trust in organizational relationships (with a focus on trust in knowledge transfer and trust as a substitute for contracts) or the management of communication (Gomes et al., 2016). For instance, the CPS might help produce valuable solutions to the difficulties caused by information asymmetry in the M\&A process as well as increase the effectiveness of the courtship period, identified as a key factor for success in the pre-acquisition phase (Gomes et al., 2013). For any problem addressed in this period, during the first stage of problem formulation, both firms will gain more information including tacit knowledge, and will improve mutual knowledge.

During the post-agreement phase, the CPS can be applied by teams composed of both firms' representatives. These teams might jointly generate, design, and assess new solutions to solve the problems, taking into account each firm's specificities, abilities, and culture. This might help to provide action plans that emphasize the need to balance the integration and reconfiguration of firm resources to guarantee success (Gomes et al., 2013). For example, CPS could be used to furnish the management teams with new ideas, help to reposition and develop new brand strategies, and increase employees' acceptance levels concerning the new partnership. The definition of standards for joint evaluation and selection criteria for the best ideas also deserves special attention. 


\section{$\underline{\text { CPS limitations }}$}

Despite its status as one of the most widely influential creative process models (Puccio et al., 2010), the CPS framework still lacks some important specifications, in particular an explicit definition of the evaluation and selection criteria (and their respective origins). Methods such as the design of a criteria grid have been suggested by other researchers (Basadur, 1994; Isaksen \& Treffinger, 2004). The CPS framework's stakeholder identification is also quite vague. Company managers and external consultants alike could be involved, but that might prove difficult considering the absence of clear direction, especially regarding the generation of evaluation and selection criteria. Stakeholders' views could enhance the process success.

Lean

\section{$\underline{\text { Lean definition }}$}

The term "Lean" first appeared in the manufacturing industry as a response to continuous improvement and efficiency maximization. "Lean manufacturing" is "an operational strategy oriented toward achieving the shortest possible cycle time by eliminating waste" (Pullan et al., 2013, p. 450). As an organizational process, Lean Product Development (LPD) develops a product with limited cost and time (Alvarez, 2015) with the aim of maximizing the value added to the different stakeholders (Tortorella et al., 2015), while minimizing the costs of product development.

Literature about Lean Product Development (LPD) is quite recent but has experienced exponential growth with numerous articles published recently on the topic. LPD is built 
around principles such as value creation, customer focus, waste reduction, continuous improvement, and process mapping (Drohomeretski et al., 2014). Beyond product development, Lean principles have also been applied to the organization itself. To maximize efficiency of its business model, organizations favor experimentation over planning, customer feedback over intuition, and iterative design over big design upfront (Blank, 2013). A corollary to these behaviors is greater interaction between teams, flexibility, and dynamism, as well as shorter development times (Reis et al., 2013). Some ventures position Lean principles at the core of their strategy, to give employees a common purpose. Collis (2016) detailed the process of a Lean strategy thus: Make the most of limited resources, learn from the market, and adjust the strategy.

\section{$\underline{\text { Lean process }}$}

Derived from operations management, Lean initially focused on reducing non-value-added activities while improving productivity (Jasti \& Kodali, 2014). Although Lean has been successfully applied for many years in manufacturing, its application in other fields has been limited (Helander et al., 2015). The Lean method proposes to "get out of the building" (Kolko, 2015) and to put the product before potential customers. LPD strives to reduce time spent on the whiteboard, working through edge cases and what-if scenarios (Wang et al., 2012). Feedback from customers is fundamental to get away from the biased-expert perspective. Similarly, it is important to put the product before stakeholders. Building on this information, the process of product design is then improved by reducing waste and resources, and by avoiding spoiling resources with unnecessary features. Data collected in 
the first stage may be combined with various development tools created especially for Lean management or for classic product development. Common techniques are Taguchi methods (a highly mathematical/calculation intensive technique), design of experiments (DOE), using a decision-making or decision support tool like quality function deployment (QFD), or failure mode effect analysis (FMEA), among others (Wang et al., 2012). Various tools/techniques have been developed to implement Lean efficiently, such as creating a flat hierarchy structure, by means of co-location, or employee empowerment (Wang et al., 2012). In the Toyota organization, for instance, the chief engineer balances functional expertise and cross-functional integration, enabling a strong principle of Lean: focusing on the customer while being able to manage teams. In conclusion, standardized methods of Lean have been mostly proposed by researchers or practitioners in manufacturing (Reinertsen \& Shaeffer, 2005).

\section{$\underline{\text { Lean outcomes }}$}

A core Lean outcome is that it promotes interaction among stakeholders (Tortorella et al., 2015), which encourages them to commit to the process of a new project (such as solving a problem, creating a product, or starting a firm). As a consequence, actors feel bound to the project. A second outcome is linked to the process of knowledge creation (Tyagi et al., 2015). The experimentation dimension of Lean helps to gather experiential knowledge, which favors radical innovation (Bicen \& Johnson, 2015). Implementing a bottom-up process ultimately leads to firm agility and to balancing opportunity- and strategy-driven mindsets (Collis, 2016). The strong focus on the customer helps to create minimum viable 
products (MVP) (Blank, 2013, p. 67). A third output of Lean is to define and identify waste (such as defects, over-processing, waiting, and overproduction) and thus favor fast action over slow. Where more traditional approaches can be rather contemplative and reflective and require systems thinking (Kolko, 2015), faster approaches seem better adapted to today's world in which the pace of innovation is increasing. Paradoxically, speed can also be favorable in the case of failure: The faster the firm fails, the less money is wasted.

\section{$\underline{\text { Lean as a framework to support formal relationships }}$}

Collaborative methods of development such as M\&A, alliances, and joint ventures are complex by nature (Gomes et al., 2013) and require many decisions throughout the process. Ex ante, collaborative methods of development raise strategic issues such as what synergies can be made with the target partner/company, how the market will react to this strategic move, and what the next move of competitors will be. Ex post, strategic issues are related to enhancing the efficiency of the new organization and repositioning customer segments. Lean management is derived from a method developed in manufacturing industries to make them more efficient. It is historically designed to guide post-collaborative methods of development such as optimizing a lengthening chain. The success of this method, combined with the general trend of manufacturers adopting more service business models (Crozet \& Milet, 2017), leads to application of Lean principles across a range of management issues, including reviewing organizational processes in new product development, for instance. This application of Lean principles is natural as restructuration follows the establishment of collaborative methods of development. Yet, despite its frequent application, Lean lacks a 
strategic dimension; it is very efficient for optimizing or developing a product in a settled organization but might present several challenges when assembling a portfolio of products in a formal partnership.

\section{$\underline{\text { Lean limitations }}$}

The literature on Lean has identified two major limitations (Tortorella et al., 2015). First, developments are built from small iterations with the customer and/or stakeholders, which can result in solutions that might well fit the environment but lack alignment with the organizations' strategies. This can lead to developing unnecessary activities, and to higher failure rates (Haque \& James-Moore, 2004).

The second challenge is also linked to the same core characteristic of Lean: Iterative development intrinsically prevents formal or standardized processes, which can lead to ineffective control of high-volume developments, poor internal communications, lack of common focus, inability to improve or learn from mistakes, and ultimately poor project deadline achievement and fiscal control (Oppenheim, 2004; Reinertsen, 2009). The literature on Lean is still in its early stages and one of its greatest challenges today is to identify good practices moderating these pitfalls (Hoppmann et al., 2011).

\section{Findings}

In this section, we start by comparing the four problem-solving frameworks before focusing on the most appropriate for formal relationships. 


\section{Comparison of the four problem-solving frameworks}

When analyzing our two initial research questions, it is our understanding that while the VCW, DT, and CPS can be used in the context of both pre- and/or post-agreement phases, Lean is more appropriate for the post-agreement phase. The major strength of the VCW is in being a meta-framework and its ability to support decision-making in both an agile and structured manner, which allows to address a much greater number of challenges in formal partnerships. While DT is appropriate for new product development, CPS to communicate among diverse teams, and Lean to optimize the production process, the VCW metaframework can be used to address all of the above challenges because it guides the overall logic of problem-solving and decision-making. More importantly, it triggers the decision to use DT, CPS, Lean, and others (such as BOS, BMC) according to the context. As such, it has the ability to overcome many of the limitations of those tools and frameworks. Table 1 compares the four problem-solving frameworks across different dimensions.

\section{Insert Table 1 about here}

Traditionally, the limitations of popular problem-solving frameworks are that they can be used only by powerful leaders (Iskander, 2018) because, to be implemented, they require resources (time, money, people) and proper training (such as traditional teaching or certification programs). Although this might be true for some problem-solving approaches, it is important to consider how existing frameworks can be more efficient and bring added value for problem-solving, given limited resources that organizations and individuals often have. 
In order to address the resource limitations of the "non-powerful" leaders, the VCW developed simpler customized tools. These tools involve offering alternative approaches, which demand fewer resources (that is, the $3 \mathrm{Ms}$ ) to address challenges. In the case of a straightforward problem/challenge, it is possible to apply a VCWsprint in a simpler and faster manner. The VCWsprint is initiated with a KDM's challenge, followed by rapid brainwriting of solutions and filters (that is, facilitators and obstacles) by a group of people, KDM's selection of ideas and ranking of the selected filters, and finally a discussion about how to implement the solutions that make it through those filters. The VCWsprint concludes with a decision about the future application of a more extended version of the VCW.

For those with some resources and more difficult problems/challenges that require carefully considered solutions supported by co-creation ${ }^{3}$, the VCW offers two alternatives. First, VCWsprints, which might take one or two days, involve co-creation with internal and/or external stakeholders, and include a limited number of tools to solve an organizational problem/challenge. Second, VCWradar training, which takes three and a half to four days. In this training, a large number of effective problem-solving tools are applied, increasing the likelihood of presenting a more robust solution for challenging problems. Finally, for organizations that do have resources (3Ms) and complex problems/challenges, the VCW offers customized VCWconsultancy projects supported by the VCW meta-framework, data from past projects, different stakeholders, and an extensive portfolio of tools.

\footnotetext{
${ }^{3}$ Additional information is available at www.ValueCreationWheel.com and www.openVCW.com.
} 


\section{VCW projects in formal relationships}

Hundreds of organizations across different sectors have collaborated with VCW teams during the last two decades. Examples of organizations include Aga Khan Development Network, Ageas, Airbus, Airbus Helicopters, Anacom, AstraZeneca/Santis, AXA, Bank of Cyprus, BéBécar, C.A. Papaellinas group, Cathay Pacific Airways, Cyta-Vodafone, Claranet, Credit Suisse, Crowne Plaza, Deimos-Elecnor Group, Everis-NTT Data, Forbach city, Flying Tiger, Four Seasons Hotel, Gemalto, GDF Suez, GirlMove, IGT, INCM, InvestLisboa, IPO Porto, ITER, Healthcare City, Jerónimo Martins, L'Oreal, Liga Portugal, Lufthansa Technik, Mastercard, McDonald's, OKTAN, Otis, Piraeus Bank, Renova, Rio Tinto Alcan, Santander, Santa Casa Misericórdia Lisboa, Technik, theCamp, Uniplaces, UPS, Vienna International Airport, among many others. Based on a review of the last three years (2016-2018) of VCW projects conducted in formal partnerships, we identified a total of 35 in which the VCW solved a wide range of problems/challenges in formal relationships across different topics and industries (see Table 2). Although the VCW is used by organizations of different sizes, due to the nature of our unit of analysis (formal relationships) the majority of the VCW cases presented in Table 2 occurred mostly in Fortune 500 and large organizations ${ }^{4}$.

\section{Insert Table 2 about here}

As seen in Table 2, a wide range of challenges have been solved in formal relationships during the last three years. The $\mathrm{VCW}$ can be used in both the pre- and post-agreement

\footnotetext{
${ }^{4}$ Sectors include aerospace, airlines, biotech, diesel, energy, hotel, industrial manufacturing, insurance, finance, healthcare and pharmacy, media, motorcycling, retailing, satellite, restaurant chains, and tourism.
} 
phases of formal agreements. For instance, in the pre-agreement phase, it can be used to choose the right strategic partner (Gomes et al., 2013; Weber et al., 1996). This is the experience of a Fortune 500 firm that used the VCW to identify which companies to partner with in order to enter new industries. Considering the high dependence of this organization on a single industry, the VCW was used to determine how to diversify the risk through cooperation with other industries while leveraging on technology advantage, know-how, and experience in their specific industry. The final outcome was to invest resources to enter the consultancy sector. In the post-agreement phase the VCW has also been used to address a wide range of challenges: change, communication, competition/coopetition, corporate governance, customer retention, decision making, distribution, growth, headquarterssubsidiary relationship, human resources management (HRM), innovation, knowledge transfer, international business, leadership, new product/service development, marketing, relationship building, sales, strategy, supply chain management, trust, governance, retailing, among many others. For the purpose of illustration, but due to space limitations, we now explore just two cases from Table 2 in more detail.

\section{$\underline{\text { VCW applied to an M\&A in the field of finance and media }}$}

This is the first of the 35 challenges mentioned in Table 2. We start with the real case of an M\&A to illustrate how the VCW can be applied to address a new challenge arising from a formal partnership. Over the years, this corporation has acquired several companies in order to expand and improve its market data services. As a consequence of being a world leader in the sector, together with the frequent acquisition of numerous companies operating 
different systems, the corporation had some technological and communication challenges as well as a vast amount of data.

In the first phase, the VCW team, together with the KDMs, started with a diagnosis of the situation. To achieve homogeneity within the corporation, the organization launched a new data platform serving the financial and media markets. However, many customers using the old products resisted using the new platform since they were happy with the products available before the M\&A. In order to keep old customers satisfied, the corporation was spending considerable resources maintaining the old databases and products compatible with today's technological standards as well as investing in communication. As a result, the major challenge facing the organization was how to convince resistant customers to switch to the new platform.

In the second phase of the VCW, the goal was to stimulate new ideas to convince resistant customers to change to the new platform. To do so, the VCW team conducted market research using sources of primary data, including external workshops and interviews with executives from customer support and with data analysts from different teams.

Additionally, for secondary research, the VCW team used three internal company reports, promotional brochures, published customer reviews and criticisms, competitor practices, and internet data. Examples of ideas generated during this phase to convince resistant customers to switch included: a range of customer services incentives (from free in-house training and promotion of economic packages to customized interfaces and making the switch compulsory); market research activities (for example about potential target markets, 
reviews and criticisms about the new platform, and segmentation of the platform according to customer needs); product adjustments (for example make the new product compatible with previous versions or readjustment of the user interface to match older/other products); pricing strategies free trial periods, discounts on services provided, giving it for free, offering reduced prices to organizations such as universities, NGOs, and governments, or increasing the price of old programs); promotional activities (for example partnerships with universities, in-house training to employees who promote the product, more advertisement and promotion of the new features to the target market); and distribution strategies (for example installment of the platform in universities for students and professors to become familiar with the product). Then the VCW team generated several criteria/filters using both secondary and primary data (brainstorming sessions and interviews with executives). Examples of criteria/filters emerging in this step include aspects associated with marketing and customer needs (for instance, lower switching cost, lower skepticism, customer willingness to change, customer satisfaction, alignment with customer expectations, large number of existing customers), financial aspects (for example, lower cost, high profit margins, high value for money), a technological solution (for instance, high technology readiness, better quality compared to previous alternatives, low application support, and low maintenance cost), competition (for example, difficult to copy by others, competitive price vs. existing alternatives), and the implementation process (for instance, easy to develop, easy to implement, fast response, low cost of implementation).

In the third phase of the VCW, the board members selected 20 ideas to address the initial challenge. Additionally, they selected a total of eight filters and ranked them as follows: 
user-friendly interface, lower skepticism, greater customer willingness to change, greater customer satisfaction, lower cost of implementation, lower price vs. competitors, easier to implement, and lower switching cost for the customer.

In the fourth phase of the VCW, all 20 ideas went through the 8 filters in the Value Creation Funnel (VCF) leading to the final solution of redesigning the platform. The VCW team them conducted a competitor analysis for the final solution to align with the attributes valued by the target market and clearly identify the value proposition and unique selling points of the new platform.

Finally, in the fifth phase of the VCW, the board developed, together with the VCW team, a business model to implement the new technological platform. A team comprising a project manager along with developers, marketers, and a representative from the customer support team initiated the plan to develop and implement a readjusted user interface similar to earlier products.

$\underline{\text { VCW innovation ecosystem involving } 27 \text { partners across } 13 \text { countries }}$

This is the second of the 35 challenges presented in Table 2. To address this challenge, the VCW helped to support the creation of an innovation ecosystem (openVCW, 2017) to minimize the risks related with managing strategic human capital (Ferrary, 2015) and managing projects across diverse corporate and national cultures (Gomes et al., 2013; Gomes et al., 2016). New methods of collaborative thinking, innovation, and planning are needed for effectively achieving the Sustainable Development Goals (Philips, 2018). The impact of governance on the effectiveness of managing a formal partnership is among the 
most complex challenges of formal relationships (Albers et al., 2016; Barkema et al., 1997; Lui \& Ngo, 2012).

Elecnor Deimos Group conducts business in four countries (Portugal, Romania, Spain, and the United Kingdom) and is the technological branch of Elecnor, a global player with a presence in more than 50 countries (Fonseca et al., 2018). Since 2015, Deimos Engineering (Deimos) in Portugal applied the VCW to address 11 different projects, some of which were very complex. This was the case of five EU/Horizon2020 projects ${ }^{5}$, where the VCW helped to achieve the Sustainable Development Goals. Often, such projects are long-term plans in which the VCW is used to support the decision-making process, transference of technology to the market, and comprises multiple VCWs to solve a sequence of challenges within the same project. As mentioned by Nuno Catarino, Head of the Data Systems Division of the Elecnor Deimos Group and Senior Project Manager at Deimos Engineering: "we worked with VCW in the development of two components: an institutional component and a commercial component." This institutional and commercial approach to the VCW was clearly reflected in the NextGEOSS Consortium, involving 27 partners from 13 different EU countries. In this project, Deimos decided to use the VCW framework to help manage this cross-cultural and cross-industry project. The VCW contributed by getting the different project stakeholders to work together in an organized manner to develop the value proposition for NextGEOSS, a web-based IT platform related to Earth observation data. According to Nuno Catarino, the VCW played a major role in this $€ 10$ million project:

\footnotetext{
${ }^{5}$ BETTER, Marine-EO, MyFarm, NextGEOSS, and SenSyF.
} 
The VCW helped to manage the consortium, definitely. [...] We wouldn't have such a targeted value proposition and public image for the project without the VCW. [...] The VCW had a huge impact. If it was not for the $V C W$, we wouldn't have passed the message and made the decision pass. [...] The biggest strength of the VCW is that you take everything into account in shaping a decision and build a solid case to get it pass the board, which would not have been easily accepted otherwise. It also connects your own views with those of the main stakeholders, which are involved in and take ownership of the whole process. The VCW is very powerful for boards because they are effectively engaged, have opportunity to give inputs without a big waste of time, avoiding long board discussions. It is about efficiency, but shared ownership. [...] You avoid all the conflicts and put all of them into the VCW process.

The fact of having a five-phase structured framework — in which the KDMs (eight members of the consortium) play a major role in VCW phases 1,3, and 5-became critical in getting all 27 partners across the 13 different countries communicating among themselves. Based on the experience gained over the last three years in the successful completion of $10 \mathrm{VCW}$ projects, the VCW is now involved in three more Horizon2020 consortiums and Deimos is working on the creation of an internal VCW Innovation Ecosystem. This will encourage industrializing innovation inside the organization while building a structured and agile framework to find solutions for Deimos' different projects. According to Vânia Fonseca, the Innovation and Sustainability Specialist at Deimos:

it is interesting to observe that during the last three years, there has been a growing involvement of the KDMs in the various VCW challenges because they are aware that their involvement will make an enormous difference in the implementation of the final solution(s).

As Nuno Catarino explained, the future of the VCW Innovation Ecosystem will become very useful: 
to systematize the innovation process and justify decisions to address different challenges. With the support of the VCW, many more ideas and criteria are generated and there will be a rationale supporting the selection of future solution(s).

People are skeptical when there is no systematized process or solid reasoning supporting the solutions to solve existing challenges.

Finally, the VCW helps to manage the paradox of choice and tech-push vs. market-pull tension. This is in line with the perspective of Nuno Ávila, the General Director at Deimos Engineering:

We have ideas every day, all the time, many more ideas than what we could accomplish. [...] The VCW is a rational way of thinking about streamlining ideas, is something useful. We start getting used to adopting this methodology [...] in multiple dimensions which all converge to business sustainability: an innovation process, to enlarge our markets, to convert part of our projects into products and, finally, to build this machine, to find how can we get the right skills. [...] VCW came to us as the easiest way to look at a multiplicity of ideas [...] and in a very objective and rational way to be able to do a very thin selection of the applications of technology which is always a big drama.

In conclusion, after applying the VCW to more than 10 projects ranging from HRM to techtransfer, the Deimos board perceives that the VCW is a decision-making framework that helps to focus on an effective output in an efficient manner, being particularly useful in managing complex problems. 


\section{Discussion and directions for further research}

This study is innovative in the sense that we match two fields that are not traditionally considered in the literature: collaborative problem-solving frameworks with formal partnerships. We intend to provide a better understanding of how problem-solving tools applied in several fields of management can be utilized to solve a wide range of challenges in the pre- and post-agreement phases of formal partnerships (see Gomes et al., 2013). The conceptualization of VCW as a decision-making framework in formal relationships could be used for IC\&C and to provide the groundwork for further theory building and testing.

The VCW is a decision-making framework supported by co-creation and collective intelligence, which helps the leaders who are KDMs to solve a problem/challenge. The VCW helps KDMs find customized and consensual solutions for problems/challenges in their domains. Practitioners and academics are encouraged to explore the reasons why KDMs perform well or perform poorly in light of internal pressures such as compensation structure and organizational culture and external pressures such as shareholder pressure and social aspirations (Schnatterly et al., 2018). The VCW has already been applied by women in leadership academies to evaluate personal development and life decisions as well as promote leadership and entrepreneurship skills (Reis-Marques et al., 2019), but much more research is required to better understand women's decision-making processes and to explore women's representation in leadership positions (Hoobler et al., 2018).

The VCW is a meta-framework, which is not meant to replace DT, CPS, Lean, or others. If any model or framework can contribute to solving a challenge/problem, then the VCW can 
integrate, augment, and/or become part of it. Conceptualization of the VCW as a

collaborative framework, which has proven itself effective in formal relationships, can inspire others to contribute to IC\&C and improvement of future performance via experiential and vicarious learning (Baum et al., 2000) or strategy restoration (Miller et al., 2018) for example.

The presentation of several VCW applications as well as the proposed conceptualization of VCW as a decision-making framework to support IC\&C has several implications for further research and practice. The VCW is a meta-framework that helps to deal with IC\&C in dynamic and changing environments. Through a method that is both structured and agile, the VCW involves the KDMs in co-creation with both internal and external stakeholders. In line with past research, the VCW supports both intra-organizational and interorganizational multidisciplinarity, supporting the transfer of know-how inside the organization and bringing knowledge in from outside (see Figure 3).

\section{Insert Figure 3 about here}

To address the challenges, the VCW builds on this inter-organizational multidisciplinarity, namely internal competencies, processes, resources, and organizational practices. The VCW might also incorporate the input of different types of external stakeholders from the initial stage of discovery to the consolidation of value, including people hitherto unfamiliar with the problem and context.

Although all frameworks have pros and cons, and there is no perfect framework, we believe that soon the trend will be for the emergence of meta-frameworks with characteristics 
similar to the VCW. New frameworks are expected to be both structured enough to focus the teams on clear goals and clarify the expected activities in an orderly manner, and agile enough to answer the demands of today's changing markets, providing space in which to be incorporated, incorporate, and/or complement the best of different frameworks, tools, and theories.

In formal partnerships there is huge potential to apply the VCW to create VCW Innovation Ecosystems and solve challenges at the board level in both the pre- and post-arrangement phases. For example, boards must manage and monitor asymmetric information and the non-executive board has the function of supervising the executive board. Consequently, there are some challenges at this level: How to overcome the fact that those who are outside the organization know less than those who are inside? How avoid conflicts of interest? When there are no clear solutions to these problems, investors will be alarmed. With the support of a VCW Innovation Ecosystem, auditors and organizations might be in a much better position to address these and many other organizational challenges at the board level.

Future research is also encouraged to compare the VCW with other well-known approaches such as Business Model Canvas (BMC) (Osterwalder \& Pigneur, 2010) and Blue Ocean Strategy (BOS) (Kim \& Mauborgne, 2004). One might say that BMC's major challenges are how to find the right value proposition and the right target markets where, over the years, the VCW has been able to identify both value propositions and the right target market in numerous projects. BOS' major strength is in presenting a "magic formula" to 
increase value while cutting costs. In this context, the VCW could be used to find out how to identify markets without competitors and how to grow in a new, uncontested market.

The VCW has been used most to address How, What, Which, and Who questions and, by the end of the process, is also able to answer questions that require deeper critical thinking skills, including Why? and When? One interesting direction for further research is to complement the VCW with Tversky and Kahneman's (1992) research in cumulative prospect theory, and Kahneman's (2011) work on the dichotomy between two modes of thought: "System 1" where the brain is fast, automatic, and intuitive; and "System 2" where the mind is slower, analytical, and reason dominates. Kahneman (2011) adds that System 1 often guides System 2. A deeper understanding of the relationship between System 1 and System 2 is extremely useful to the further development of the VCW as a decision-making process supported by profound analysis. Moreover, the incorporation of techniques from neuroscience could bring added value to the VCW (by defining criteria/filters, for instance), help to better understand why people use System 1 to replace complex questions with simpler ones (Kahneman, 2011), and take uncorroborated and irrational decisions.

Finally, the great majority of frameworks are like fire; they can be used for good as well as bad purposes. To our knowledge, the great majority of existing frameworks do not establish any application pre-conditions at this level. The VCW is an exception because it establishes as a pre-condition that, before starting a new VCW project, leaders need to be willing to build on five pillars: sustainability, common good, collaboration, wisdom, and transparency. Moreover, at the end of the project, the KDMs and the VCW team should 
ensure that the project was developed consciously through application of the five VCW pillars. A "WDV-World Development Vision" certificate is awarded to the people behind those projects that are clearly supported by the five VCW pillars (VCW, 2019). The Upper Echelons Theory indicates that organizational outcomes are partially correlated with the characteristics of top management (Hambrick \& Mason, 1984). Further research is encouraged to ensure that management frameworks are not being used incorrectly. Moreover, research should investigate how leadership styles (Gabarro \& Kotter, 2005; Goleman, 2000; Goleman et al., 2013; Shuibo \& Tianbing, 2011), top management characteristics, and CEO profiles (Chatterjee \& Hambrick, 2007; Chen et al., 2015; Galasso \& Simcoe, 2011; Goel \& Thakor, 2008; Mackey, 2008) explain KDMs’ behavior, especially with regard to VCW phases 1,3 , and 5.

In conclusion, after two decades of projects conducted in more than 20 countries, across different industries, challenges, and contexts, the VCW decision-making framework can now help KDMs and society to create shared value (Porter \& Kramer, 2011) and effectively solve inter-organizational challenges in formal relationships (such as M\&A, strategic alliances, joint ventures, franchises, global value chains, and business model restructuring). Many research avenues remain open for further exploration in the years to come. 


\section{References}

Albers, S., Wohlgezogen, F., \& Zajac, E. J. (2016). Strategic alliance structures in organization design perspective. Journal of Management, 42(3), 582-614.

Allemand, I., Brullebaut, B., Galia, F., \& Zenou, E. (2017). Which board members when you innovate? Board selection as a strategic change for innovation. Strategic Change, 26(4), 311-322.

Alvarez, J. C. (2015). Lean design for Six Sigma. International Journal of Quality \& Reliability Management, 32(8), 895-905.

Asseraf, Y., Lages, L. F., \& Shoham, A. (2018). Assessing the drivers and impact of international marketing agility. International Marketing Review, 32(2), 289-315. doi:10.1108/IMR-12-2017-0267.

Barkema, H. G., Shenkar, O., Vermeulen, F., \& Bell, J. H. (1997). Working abroad, working with others: How firms learn to operate international joint ventures. Academy of Management Journal, 40(2), 426-442.

Basadur, M. (1994). Simplex: A flight to creativity. Buffalo, NY: Creative Education Foundation.

Beamish, P. W., \& Lupton, N. C. (2016). Cooperative strategies in international business and management: Reflections on the past 50 years and future directions. Journal of World Business, 51(1), 163-175.

Beverland, M. B., Wilner, S. J., \& Micheli, P. (2015). Reconciling the tension between consistency and relevance: Design thinking as a mechanism for brand ambidexterity. Journal of the Academy of Marketing Science, 43(5), 589-609.

Bicen, P., \& Johnson, W. H. (2015). Radical innovation with limited resources in highturbulent markets: The role of lean innovation capability. Creativity and Innovation Management, 24(2), 278-299.

Blank, S. (2013). Why the lean start-up changes everything. Harvard Business Review, 91(5), 63-72.

Brouthers, K. D., \& Bamossy, G. J. (2006). Post-formation processes in eastern and western European joint ventures. Journal of Management Studies, 43(2), 203-229.

Brown, T. (2010). Change by design. New York, NY: Harper Collins.

Buckley, P. J., Glaister, K. W., Klijn, E., \& Tan, H. (2009). Knowledge accession and knowledge acquisition in strategic alliances: The impact of supplementary and complementary dimensions. British Journal of Management, 20(4), 598-609.

Carlgren, L., Elmquist, M., \& Rauth, I. (2014a). Design thinking: Exploring values and effects from an innovation capability perspective. The Design Journal, 17(3), 403-423. 
Carlgren, L., Elmquist, M., \& Rauth, I. (2014b). Exploring the use of design thinking in large organizations: Towards a research agenda. Swedish Design Research Journal, 1(14), 47-56.

Carlgren, L., Elmquist, M., \& Rauth, I. (2016). The challenges of using design thinking in industry: Experiences from five large firms. Creativity and Innovation Management, 25(3), 344-362.

Carlgren, L., Rauth, I., \& Elmquist, M. (2016). Framing design thinking: The concept in idea and enactment. Creativity and Innovation Management, 25(1), 38-57.

Carmeli, A., Zivan, I., Gomes, E., \& Markman, G. D. (2017). Underlining micro sociopsychological mechanisms of buyer-supplier relationships: Implications for interorganizational learning agility. Human Resource Management Review. doi:10.1016/j.hrmr.2016.12.002

Chatterjee, A., \& Hambrick, D. C. (2007). It's all about me: Narcissistic chief executive officers and their effects on company strategy and performance. Administrative Science Quarterly, 52(3), 351-386.

Chen, G., Crossland, C., \& Luo, S. (2015). Making the same mistake all over again: CEO overconfidence and corporate resistance to corrective feedback. Strategic Management Journal, 36(10), 1513-1535.

Collis, D. (2016). Lean strategy. Harvard Business Review, 94(3), 62-68.

Contractor, F. J., \& Woodley, J. A. (2015). How the alliance pie is split: Value appropriation by each partner in cross-border technology transfer alliances. Journal of World Business, 50(3), 535-547.I

Crozet, M., \& Milet, E. (2017). Should everybody be in services? The effect of servitization on manufacturing firm performance. Journal of Economics and Management Strategy, 26(4), 820-841. doi:10.1111/jems./12211

Doz, Y. L. (1996). The evolution of cooperation in strategic alliances: Initial conditions or learning processes? Strategic Management Journal, 17, 55-83.

Doz, Y. L., Olk, P. M., \& Ring, P. S. (2000). Formation processes of R\&D consortia: Which path to take? Where does it lead? Strategic Management Journal, 21, 239-266.

Drohomeretski, E., Gouvea da Costa, S. E., Pinheiro de Lima, E., \& Garbuio, P. A. D. R. (2014). Lean, Six Sigma and Lean Six Sigma: An analysis based on operations strategy. International Journal of Production Research, 52(3), 804-824.

Drucker, P. F. (1984). The new meaning of corporate social responsibility. California Management Review, 26(2), 53-63.

Ferrary, M. (2015). Investing in transferable strategic human capital through alliances in the luxury hotel industry. Journal of Knowledge Management, 19(5), 1007-1028. 
Fonseca, V., Lages, L. F., \& Kim, P. H. (2018). Deimos: Expanding to a new market using the Value Creation Wheel (Case BAB370-PDF-ENG, Babson College). Boston, MA: Harvard Business Publishing.

Gabarro, J. J., \& Kotter, J. P. (2005). Managing your boss. Harvard Business Review, $83(1), 62-69$.

Galasso, A., \& Simcoe, T. S. (2011). CEO overconfidence and innovation. Management Science, 57(8), 1469-1484.

Glaister, K. W., \& Buckley, P. J. (1996). Strategic motives for international alliance formation. Journal of Management Studies, 33(3), 301-332.

Goel, A. M., \& Thakor, A. V. (2008). Overconfidence, CEO selection, and corporate governance. The Journal of Finance, 63(6), 2737-2784.

Goleman, D. (2000). Leadership that gets results. Harvard Business Review, 78(2), 4-17.

Goleman, D., Boyatzis, R. E., \& McKee, A. (2013). Primal leadership: Unleashing the power of emotional intelligence. Boston, MA: Harvard Business Review Press.

Gomes, E., Angwin, D. N., Weber, Y., \& Tarba, S. Y. (2013). Pre- and post-M\&A connections for improved performance. Thunderbird International Business Review, 55(1), 13-35.

Gomes, E., Barnes, B. R., \& Mahmood, T. (2016). A 22 year review of strategic alliance research in the leading management journals. International Business Review, 25(1), 1527.

Gomes, E., Weber, Y., Brown, C., \& Tarba, S. Y. (2011). Mergers, acquisitions, and strategic alliances: Understanding the process. Basingstoke, UK: Palgrave Macmillan.

Hambrick, D. C., \& Mason, P. A. (1984). Upper echelons: The organization as a reflection of its top managers. The Academy of Management Review, 9(2), 193-206.

Haque, B., \& James-Moore, M. (2004). Applying lean thinking to new product introduction. Journal of Engineering Design, 15(1), 1-31.

Helander, M., Bergqvist, R., Stetler, K. L., \& Magnusson, M. (2015). Applying lean in product development: Enabler or inhibitor of creativity? International Journal of Technology Management, 68(1-2), 49-69.

Hemonnet-Goujot, A., Fabbri, J., \& Manceau, D. (2016). Crowdsourcing vs Design Thinking: Une étude comparative de deux démarches d'innovation externe dans la phase d'idéation. Décisions Marketing, 83(3), 123-139.

Hemonnet-Goujot, A., Manceau, D., \& Abecassis-Moedas, C. (2019). Drivers and pathways of NPD success in the marketing-external design relationship. Journal of Product Innovation Management, 36(2), 196-223. 
Hillebrand, B., \& Biemans, W. G. (2003). The relationship between internal and external cooperation: Literature review and propositions. Journal of Business Research, 56, $735-743$.

Hoobler, J. M., Masterson, C. R., Nkomo, S. M., \& Michel, E. J. (2018). The business case for women leaders: Meta-analysis, research critique, and path forward. Journal of Management, 44(6), 2473-2499.

Hoppmann, J., Rebentisch, E., Dombrowski, U., \& Zahn, T. (2011). A framework for organizing lean product development. Engineering Management Journal, 23(1), 3-15.

Isaksen, S. G., \& Treffinger, D. J. (2004). Celebrating 50 years of reflective practice: Versions of creative problem solving. Journal of Creative Behavior, 38(2), 75-101.

Iskander, N. (2018). Design thinking is fundamentally conservative and preserves status quo. Harvard Business Review, September.

Jahanmir, S. F., \& Lages, L. F. (2015). The lag-user method: Using laggards as a source of innovative ideas. Journal of Engineering and Technology Management, 37(Jul-Sep), $65-77$.

Jasti, N. V. K., \& Kodali, R. (2014). Lean production: Literature review and trends. International Journal of Production Research, 53(3), 867-885.

Johansson-Sköldberg, U., Woodilla, J., \& Çetinkaya, M. (2013). Design thinking: Past, present and possible futures. Creativity and Innovation Management, 22(2), 121-146.

Kahneman, D. (2011). Thinking, fast and slow. New York, NY: Farrar, Straus and Giroux.

Kieser, A. (1994). Book reviews: Geert Hofstede: Cultures and organizations. Software of the mind: 1991, Maidenhead, UK: McGraw-Hill. 279 pages. Organization Studies, 15(3), 457-460.

Kim, W. C., \& Mauborgne, R. (2004). Blue ocean strategy. Harvard Business Review, $82(10), 76-84$.

Kolko, J. (2015). Lean doesn't always create the best products. Harvard Business Review, May.

Lages, L. F. (1999). Marketing lessons from Portuguese wine exporters: The development and application of a conceptual framework. Journal of Wine Research, 10(2), 123-132.

Lages, L. F. (2000a). A conceptual framework of the determinants of export performance: Reorganizing key variables and shifting contingencies in export marketing. Journal of Global Marketing, 13(3), 29-51.

Lages, L. F. (2016). VCW-Value Creation Wheel: Innovation, technology, business, and society. Journal of Business Research, 69(11), 4849-4855. 
Lages, L. F., Jap, S. D., \& Griffith, D. A. (2008). The role of past performance in export ventures: A short-term reactive approach. Journal of International Business Studies, 39(2), 304-325.

Lee, Y. W. (2019). Enhancing shared value and sustainability practices of global firms: The case of Samsung Electronics. Strategic Change, 28, 139-145.

Leonard, D., \& Rayport, J. F. (1997). Spark innovation through empathic design. Harvard Business Review, 75(6), 102-115.

Lewis, R. (2014). How different cultures understand time. Business Insider. Retrieved from https://www.businessinsider.com/how-different-cultures-understand-time-2014$5 ? \mathrm{r}=\mathrm{US} \& \mathrm{IR}=\mathrm{T}$

Liedtka, J. (2011). Learning to use design thinking tools for successful innovation. Strategy \& Leadership, 39(5), 13-19.

Liedtka, J. (2015). Perspective: Linking design thinking with innovation outcomes through cognitive bias reduction. Journal of Product Innovation Management, 32(6), 925-938.

Lui, S. S., \& Ngo, H.-Y. (2012). Drivers and outcomes of long-term orientation in cooperative relationships. British Journal of Management, 23, 80-95.

Luo, Y. (2001). Antecedents and consequences of personal attachment in cross-cultural cooperative ventures. Administrative Science Quarterly, 46(2), 177-201.

Mackey, A. (2008). The effect of CEOs on firm performance. Strategic Management Journal, 29(12), 1357-1367.

Martin, R. L. (2009). The design of business: Why design thinking is the next competitive advantage. Boston, MA: Harvard Business Press.

McManus, J. (2019). The creation of shared value: Reconnecting business and society: An overview. Strategic Change, 28(2) , 113-114.

Mendy, J. (2019). Supporting the creation of shared value. Strategic Change, 28, 157-161.

Micheli, P., Wilner, S. J. S., Bhatti, S. H., Mura, M., \& Beverland, M. B. (2019). Doing design thinking: Conceptual review, synthesis, and research agenda. Journal of Product Innovation Management, 36(2), 124-148.

Miller, K. D., Gomes, E., \& Lehman, D. W. (2018). Strategy restoration. Long Range Planning, 52(5). doi:10.1016/j.1rp.2018.10.005

Mudambi, S. M., \& Tallman, S. (2010). Make, buy or ally? Theoretical perspectives on knowledge process outsourcing through alliances. Journal of Management Studies, 47, 1434-1456.

Nussbaum, B. (2011). Design thinking is a failed experiment. So what's next? Retrieved from http://www.fastcodesign.com/1663558 
openVCW (2017). What was the impact of the creation of a VCW Ecosystem? Retrieved from www.openVCW.com

Oppenheim, B. (2004). Lean product development flow. Systems Engineering, 7(4), 2-2. doi:10.1002/sys.20014

Osborn, A. F. (1953). Applied imagination, principles and procedures of creative thinking ( $3^{\text {rd }}$ Ed.). New York, NY: Charles Schribner's Sons.

Osterwalder, A., \& Pigneur, Y. (2010). Business model generation: A handbook for visionaries, game changers, and challengers. Hoboken, NJ: John Wiley \& Sons.

Parkhe, A. (1993). Strategic alliance structuring: A game theoretic and transaction cost examination of interfirm cooperation. The Academy of Management Journal, 36(4), 794-829.

Parnes, S. J. (1967). Creativity behavior guidebook. New York, NY: Charles Schribner's Sons.

Philips, F. (2018). Innovation for sustainability. Strategic Change, 27(6), 539-542.

Porter, M. E., \& Kramer, M. (2011). Creating shared value. Harvard Business Review, $89(1-2), 62-77$.

Puccio, G. (1999). Creative problem solving preferences: Their identification and implications. Creativity and Innovation Management, 8(3), 171-178.

Puccio, G. J., Cabra, J. F., Fox, J. M., \& Cahen, H. (2010). Creativity on demand: Historical approaches and future trends. Artificial Intelligence for Engineering Design, Analysis and Manufacturing, 24(2), 153-159.

Pullan, T. T., Bhasi, M., \& Madhu, G. (2013). Decision support tool for lean product and process development. Production Planning \& Control, 24(6), 449-464.

Reinertsen, D. G. (2009). The principles of product development flow: Second generation lean product development. Redondo Beach, CA: Celeritas Publishing.

Reinertsen, D., \& Shaeffer, L. (2005). Making R\&D lean. Research Technology Management, 48(4) , 5 1-57. doi:10.1080/08956308.2005.11657325

Reis, Z. C., Costa, C. A., Milan, G. S., \& Eberle, L. (2013). Revisão da literatura sobre a implementação da filosofia lean no PDP: Processo de desenvolvimento de produtos. Revista Global Manager, 13(1) , 56-79.

Reis-Marques, C., Lages, L. F., \& Caminati, V. V. (2019). VCW for social impact in a developing country: Personal development and entrepreneurship in a leadership academy. In D. Z. Basil, G. Diaz-Meneses, \& M. D. Basil (Eds.), Social marketing in action: Cases from around the world (pp. 141-162). Cham, Switzerland: Springer 
Reuer, J. J., Zollo, M., \& Singh, H. (2002). Post-formation dynamics in strategic alliances. Strategic Management Journal, 23(2), 135-151.

Ricard, A., \& Saiyed, A. A. (2015). Attitude toward internationalization and early internationalization: Comparison of Indian and French SMEs' decision makers. M@n@gement,18(1),54-77.

Schnatterly, K., Gangloff, K. A., \& Tuschke, A. (2018). CEO wrongdoing: A review of pressure, opportunity, and rationalization. Journal of Management, 44(6), 2405-2432.

Seidel, V. P., \& Fixson, S. K. (2013). Adopting design thinking in novice multidisciplinary teams: The application and limits of design methods and reflexive practices. Journal of Product Innovation Management, 30(S1), 19-33.

Shuibo, X., \& Tianbing, Z. (2011). Culture clash in the boardroom. Harvard Business Review, 89(9), 129-133.

Sousa, F.C., Monteiro, I.P., Walton, A.P. \& Pissarra, J. (2014). Adapting creative problem solving to an organizational context: a study of its effectiveness with a student population. Creativity and innovation management, 23(2), 111-120.

Stettner, U., \& Lavie, D. (2014). Ambidexterity under scrutiny: Exploration and exploitation via internal organization, alliances, and acquisitions. Strategic Management Journal, 35(13), 1903-1929.

Tortorella, G. L., Marodin, G. A., Fettermann, D. D. C., \& Fogliatto, F. S. (2015). Relationships between lean product development enablers and problems. International Journal of Production Research, 54(10), 2837-2855.

Tversky, A., \& Kahneman, D. (1992). Advances in prospect theory: Cumulative representation of uncertainty. Journal of Risk and Uncertainty, 5(4), 297-323.

Tyagi, S., Cai, X., Yang, K., \& Chambers, T. (2015). Lean tools and methods to support efficient knowledge creation. International Journal of Information Management, 35(2), 204-214.

VCW (2019), Homepage. Retrieved from www.ValueCreationWheel.com

Vendrell-Herrero, F., Gomes, E., Bustinza, O. F., \& Mellahi, K. (2018). Uncovering the role of cross-border strategic alliances and expertise decision centralization in enhancing product service-service innovation in MMMEs. International Business Review, 27(4), 814-825.

Veryzer, R. W., \& Borja de Mozota, B. (2005). The impact of user-oriented design on new product development: An examination of fundamental relationships. Journal of Product Innovation Management, 22(2), 128-143.

Villax, P. (2017). What is the VCW? Retrieved from www.openVCW.com 
Wang, L., Ming, X. G., Kong, F. B., Li, D., \& Wang, P. P. (2012). Focus on implementation: A framework for lean product development. Journal of Manufacturing Technology Management, 23(1), 4-24.

Weber, Y., Shenkar, O., \& Raveh, A. (1996). National and corporate culture fit in mergers/acquisitions: An exploratory study. Management Science, 42(8), 1215-1227.

Wong, A., Wei, L., Yang, J., \& Tjosvold, D. (2017). Productivity and participation values for cooperative goals to limit free riding and promote performance in international joint ventures. Journal of World Business, 52(6), 819-830. 


\section{Short Bios:}

Luis Filipe Lages" is Director of the "VCW Lab at Nova SBE" and Full Professor at Nova School of Business and Economics, Universidade Nova de Lisboa, Portugal. He is the creator of the VCW and his fields of interest are value creation, innovation, co-creation, decision-making, problem-solving, marketing, and international business. He was recipient of the 2018 Excellence in Research Award of the American Marketing Association SIG in Global Marketing for his 2008 JIBS paper.

Antonin Ricard is Assistant Professor at Aix-Marseille University, Graduate School of Management-IAE, France and Co-Director of the entrepreneurial legitimacy research chair. His research interests are centered on international entrepreneurship and innovation. His latest research concerns determinants of decision and performance, internationalization process, legitimacy, intrapreneurship, and Emerging Market Multinational Enterprises

Aurélie Hemonnet-Goujot is Assistant Professor at Aix-Marseille University, Graduate School of Management - IAE, France. Her research interests include marketing and innovation with a specific focus on new product development (NPD) process, design management, inter-organizational collaboration, and co-creation.

Anne-Marie Guerin is Assistant Professor at Aix-Marseille University, Graduate School of Management-IAE, France. Her interests are centered on entrepreneurship and innovation and include research on new product development process, innovation in services, and pedagogical innovation.

\footnotetext{
${ }^{6} \underline{\text { flages@novasbe.pt corresponding author }}$
} 